\title{
Fractional Cooling Strategy of the Hot-Stamping Process and Its Influence on Formability and Mechanical Properties of Ultra-High- Strength Steel Parts
}

\author{
Xian-Hong Han ${ }^{1} \cdot$ Cheng-Long Wang $^{1} \cdot$ Si-Si Chen ${ }^{1,2} \cdot$ Jun Chen ${ }^{1}$ \\ Received: 5 July 2018/Revised: 15 August 2018/Published online: 11 October 2018 \\ (C) The Chinese Society for Metals and Springer-Verlag GmbH Germany, part of Springer Nature 2018
}

\begin{abstract}
The effects of forming temperature on the formability and product properties of hot-stamping boron steel B1500HS were investigated. Based on the fractional cooling strategy, boron steel sheets were heated to achieve full austenitization before they were removed from the furnace and cooled to the forming temperature using different cooling methods. Subsequently, they were simultaneously press-formed and quenched inside the tool until the martensitic transformation was finished. A series of thermal tensile tests were conducted to study the effects of forming temperatures on the stamping performance indices, including elongation, yield ratio, and hardening exponent. Then, the mechanical properties and microstructures of the hot-stamped products were characterized. Finally, an irregular part was formed using different fractional cooling strategies, while its formability and springback phenomena were discussed. The results show that using a fast-cooling method to reach $650{ }^{\circ} \mathrm{C}$ as the forming temperature optimizes the formability of the tested B1500HS boron steel. The best mechanical properties and smallest springback values were achieved using this optimal strategy.
\end{abstract}

Keywords Hot-stamping $\cdot$ Fractional cooling $\cdot$ Forming temperature $\cdot$ Formability

\section{Introduction}

Hot-stamping technology has been widely used in automotive and other manufacturing industries to produce highstrength steel parts [1]. During hot-stamping, a boron steel blank is heated to $\sim 900{ }^{\circ} \mathrm{C}$ and kept in a furnace for nearly $5 \mathrm{~min}$ to ensure homogenous austenitization. The hot blank is then quickly transferred to a tool to conduct the forming process. Because the tool has a relatively low temperature, supplied by a cooling system, the quenching process of the blank is performed inside the tool simultaneously $[2,3]$. The microstructure of boron steel post-hotstamping is primarily martensite, and its strength reaches $1500 \mathrm{MPa}$ or higher [4].

Available online at http://link.springer.com/journal/40195

Jun Chen

jun_chen@sjtu.edu.cn

1 Department of Plasticity Technology, School of Materials Science and Engineering, Shanghai Jiao Tong University, Shanghai 200030, China

2 SAIC General Motors Co., Ltd, Shanghai 201206, China
Studies of process parameters on hot-stamping technology have been conducted in recent decades mainly to find optimized parameter combinations for realizing high mechanical properties and low cycling time. Such process parameters-e.g., the forming temperature, cooling rate and austenitizing time- that affect the thermal forming process have attracted a great attention. Mori et al. [4] provided an overview of the state-of-the-art in hot-stamping processes, which included the effects of these process parameters. Liu et al. [5] considered three main factors that affected hot-stamping qualities of the high-strength steel BR1500HS, including the blank holder force, forming temperature, and tool temperature. The experimental results indicated that the forming temperature had a larger impact than others. Cui et al. [6] discussed the effects of blank geometry, forming temperature, and stamping velocity on the forming quality. They also demonstrated that the forming temperature played an important role, especially when the temperature was close to the phase transformation point. Moreover, Rong et al. [7] presented different methods to investigate the formability of highstrength steel sheets at elevated temperatures. In addition, some researches such as literature [8] were performed 
concerning the effects of process parameters on the springback during hot stamping. The importance of forming temperature was addressed as well [9].

Meanwhile, the cooling rate is another key parameter. Naderi et al. [10] conducted hot-stamping experiments on four high-strength alloyed steels using water and nitrogen cooling media. Different formability and microstructures were found owing to the varied cooling rates, which were also noted by Nishibata et al. [11]. Maeno et al. [12] used a servo press to retard the temperature decrease by reducing the contact time between the die and the blank for improving the formability. Maeno et al. [13] found that hot-stamping parts can be quenched within dies or in water when held at the bottom dead center to improve the productivity of the hot-stamping process. Zhao et al. [14] proposed a rapid cooling pretreatment to solve the cracking issues of hot-stamped steels. Ganapathy et al. [15] proposed a new hot-stamping process with pre-cooling to improve the ductility of boron steel, and the productivity of the hot-stamping process was improved as well.

In this study, effects of forming temperature on the formability and product properties of hot-stamping boron steel B1500HS were investigated. Based on the fractional cooling strategy, the quenching process was divided into two steps-the one before stamping and the one after stamping. A series of thermal tensile tests were conducted to obtain the stress-strain curves from which the formability under different temperatures was deduced. Then, the final mechanical properties and microstructures after the application of different fractional cooling strategies were characterized. Finally, typical experimental parts having unequal height and width were formed at different forming temperatures. In addition, the springback phenomenon and formability were compared and discussed.

\section{Thermal Tensile Tests}

\subsection{Material Characteristics and Experimental Scheme}

Uncoated and cold-rolled boron steel B1500HS blank samples produced by the BaoSteel Co. were used as the hot-stamping steel [16]. The blank thickness was $1.4 \mathrm{~mm}$. Table 1 shows the chemical composition of B1500HS. Its original microstructures are ferrite and pearlite. The $M_{\mathrm{s}}$ and

Table 1 Chemical compositions (wt\%) of B1500HS

\begin{tabular}{llllllll}
\hline $\mathrm{C}$ & $\mathrm{Si}$ & $\mathrm{Mn}$ & $\mathrm{Al}$ & $\mathrm{B}$ & $\mathrm{S}$ & $\mathrm{P}$ & $\mathrm{Cr}$ \\
\hline 0.23 & 0.24 & 1.3 & 0.046 & 0.0026 & 0.002 & 0.022 & 0.174 \\
\hline
\end{tabular}

$M_{\mathrm{f}}$ of B1500HS are $373{ }^{\circ} \mathrm{C}$ and $235^{\circ} \mathrm{C}$, respectively, with the critical cooling rate of martensitic transformation being $27{ }^{\circ} \mathrm{C} \mathrm{s}^{-1}$ [17].

Isothermal tensile tests were conducted to study the thermal flow behavior of B1500HS and analyze the influence of the forming temperature expressed as $Q_{T}$. Similar works for 22MnB5 can be found in a previous report [18]. In this study, the steel blank was cut into tensile specimens as shown in Fig. 1.

To simulate the actual production process, the specimens were heated and maintained at $920{ }^{\circ} \mathrm{C}$, at a heating rate of $10{ }^{\circ} \mathrm{C} \mathrm{s}^{-1}$, for $5 \mathrm{~min}$. The specimens were then quenched to a certain temperature $\left(600{ }^{\circ} \mathrm{C} / 650{ }^{\circ} \mathrm{C} / 700{ }^{\circ} \mathrm{C} /\right.$ $800{ }^{\circ} \mathrm{C} / 850^{\circ} \mathrm{C}$ ) at a cooling rate of $80^{\circ} \mathrm{C} \mathrm{s}^{-1}$. Subsequently, isothermal tensile tests were conducted at a strain rate of $0.1 \mathrm{~s}^{-1}$ to obtain the stress-strain curves. Indicators of stamping performance were calculated, including elongation and the hardening exponent $n$. For each set of parameters, three tests were performed, and the average values were calculated for analysis.

\subsection{Results and Discussion}

The stress-strain curves are plotted in Fig. 2. It can be seen that the forming temperature significantly affects the flow stress of B1500HS steel. By increasing the temperature, the flow stress gradually declined. This result agrees well with a previous report [19].

To investigate the influence of different temperatures, the stress-strain curves were fitted using a simple power function, $\sigma=K \varepsilon^{n}$. Table 2 lists the results of the stamping performance indicators.

Figure 3 illustrates the variations of the yield strength, the yield ratio-expressed as yield strength/tensile strength, elongation and the hardening exponent. Low yield strength reduces the requirement of press tonnage during production. The yield strength decreased continuously by increasing temperature, which is consistent with many other steels. All these strengths, as shown in Fig. 3a, remained at an acceptable low level. Yield ratio is an important index during the forming process. A small yield ratio implies a large feasible plastic range. As shown in Fig. $3 b$, the yield ratio first decreased and subsequently

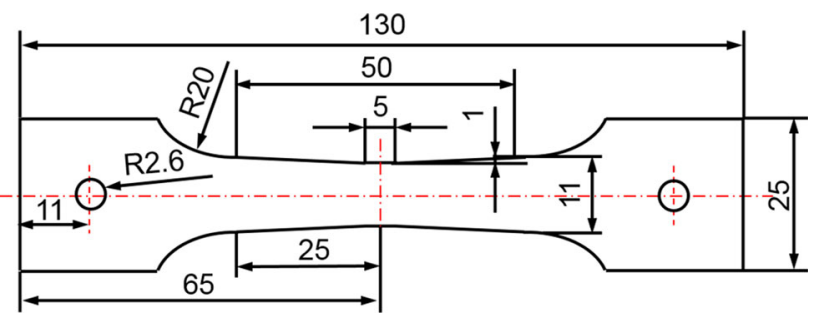

Fig. 1 Specimen for thermal tensile tests (unit: $\mathrm{mm}$ ) 


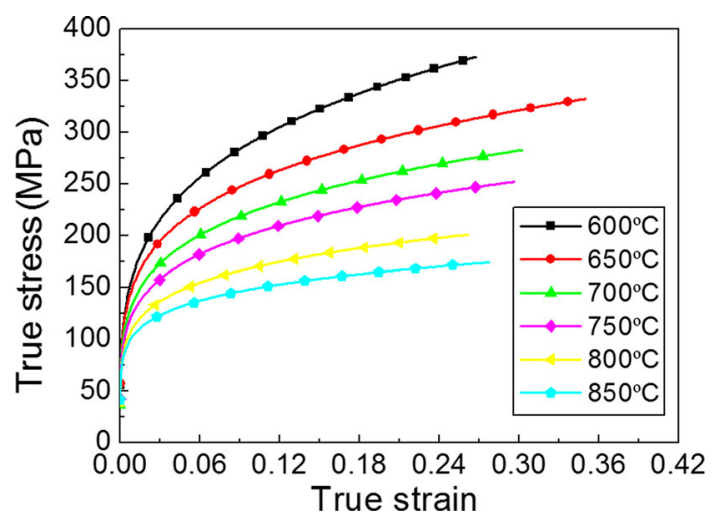

increased. It reached the minimum at $650{ }^{\circ} \mathrm{C}$. On the contrary, the elongation first increased to a maximum at $650{ }^{\circ} \mathrm{C}$ and then decreased, as shown in Fig. 3c, which also implies that the plasticity of $\mathrm{B} 1500 \mathrm{HS}$ reached the maximum value at the formation temperature of $650{ }^{\circ} \mathrm{C}$. Figure $3 \mathrm{~d}$ presents a decline curve of the hardening exponent $n$ as the temperature increased, and similar results are shown in the literature [20]. It is known that a large hardening exponent can lead to uniform deformation, thereby reducing the local thinning of the blank and increasing the limit deformation parameters [21]. Overall, considering all these indicators, the temperature of $650{ }^{\circ} \mathrm{C}$

Fig. 2 True stress-strain curves at different forming temperatures

Table 2 Results of the stamping performance indicators against the forming temperature

\begin{tabular}{llllll}
\hline Forming temperature $\left({ }^{\circ} \mathrm{C}\right)$ & Yield strength $(\mathrm{MPa})$ & Tensile strength $(\mathrm{MPa})$ & Yield ratio & Elongation & Hardening exponent, $n$ \\
\hline 600 & 159 & 324 & 0.491 & 0.269 & 0.25 \\
650 & 143 & 294 & 0.486 & 0.344 & 0.21 \\
700 & 131 & 259 & 0.506 & 0.309 & 0.21 \\
750 & 122 & 230 & 0.530 & 0.305 & 0.19 \\
800 & 106 & 191 & 0.555 & 0.292 & 0.18 \\
850 & 94 & 163 & 0.577 & 0.271 & 0.15 \\
\hline
\end{tabular}

(a)

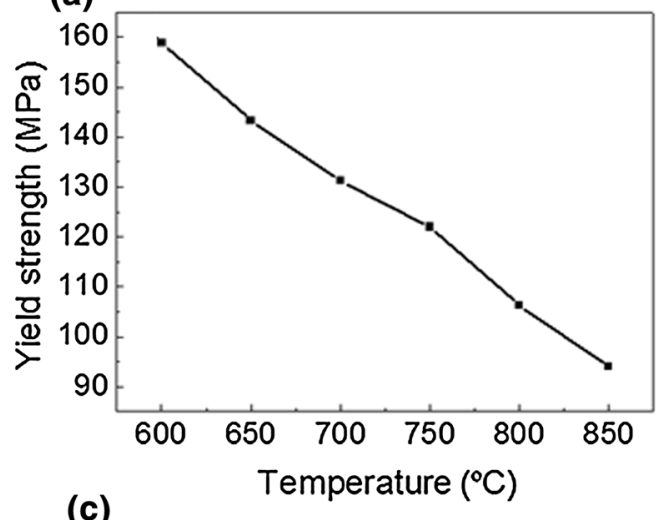

(c)

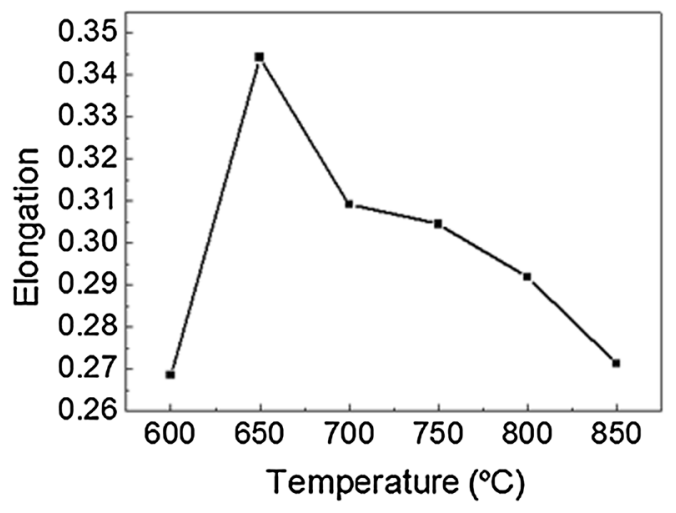

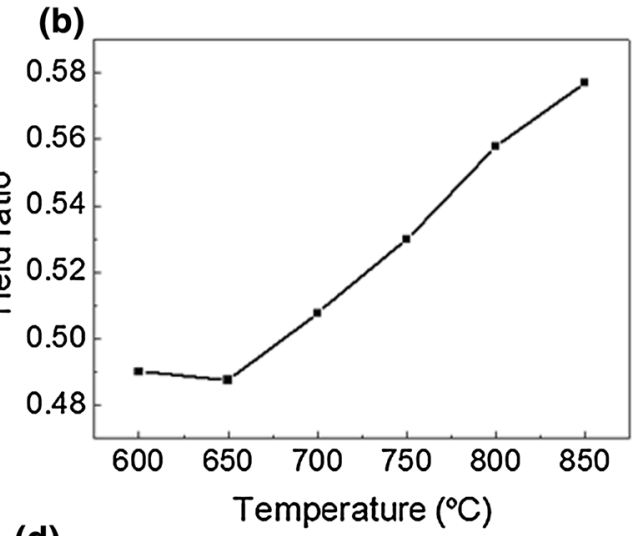

(d)

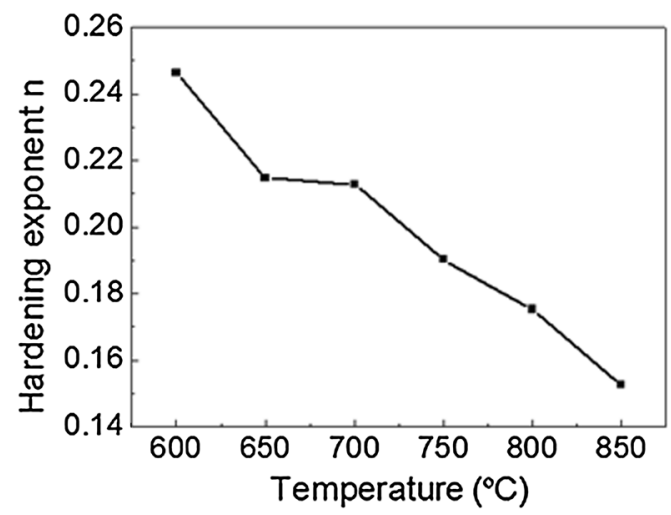

Fig. 3 Stamping performance indicators at different forming temperatures: a yield strength, $\mathbf{b}$ yield ratio, $\mathbf{c}$ elongation, $\mathbf{d}$ hardening exponent $n$ 
can be regarded as the optimal forming temperature for B1500HS steel.

\section{Mechanical Properties and Microstructures}

\subsection{Experimental Scheme}

This section discusses the effects of cooling strategies on mechanical properties and microstructures of the final hotstamping products. Figure 4 shows the experimental scheme. Cooling rates for two stages were fixed as $80{ }^{\circ} \mathrm{C} \mathrm{s}^{-1}$ and $30{ }^{\circ} \mathrm{C} \mathrm{s}^{-1}$, respectively. The cut-off point called as the forming temperature $Q_{T}$ was changed from 550 to $920{ }^{\circ} \mathrm{C}$. It should be noted that this experiment primarily focused on the effect of temperature design, no real forming process happened here. All these treatments

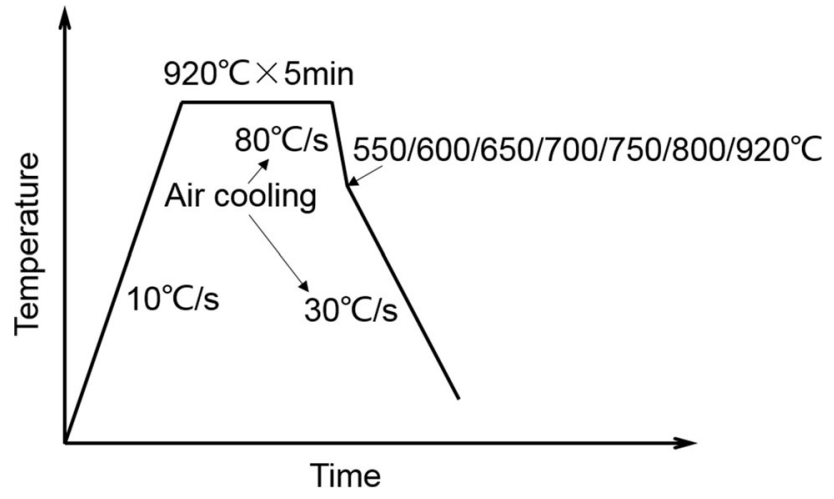

Fig. 4 Thermal simulation scheme for the fractional cooling process

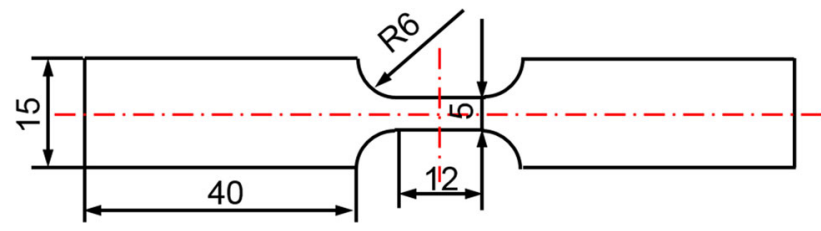

Fig. 5 Tensile specimen geometry for the thermal simulation experiments (unit: $\mathrm{mm}$ ) were performed in a Gleeble 3500 thermomechanical simulator under vacuum condition. The compressed air was used as the quenching medium. Following this, the mechanical properties were obtained by tensile tests at room temperature through Zwick/Roell Z100 machine at a tensile rate of $1 \mathrm{~mm} / \mathrm{min}$. Figure 5 illustrates the geometry of the tensile specimen.

\subsection{Results and Discussion}

Table 3 shows the results of mechanical properties postthermal simulation experiments. The tensile strengths were close to each other for different $Q_{T}$. However, the elongations presented notable variation as $Q_{T}$ changed. When $Q_{T}$ was lower than $650{ }^{\circ} \mathrm{C}$, the elongation reached $12.8 \%$ that is $22 \%$ higher than that at a $Q_{T}$ of $920{ }^{\circ} \mathrm{C}$. As a comprehensive mechanical index [22], the product of strength and plasticity at $650{ }^{\circ} \mathrm{C}$ was also high, up to 19.6 $\mathrm{GPa} \%$. Similar phenomena can also be found in a previous report [23].

Figure 6 shows the microstructures of B1500HS after heat treatments with $Q_{T}=920^{\circ} \mathrm{C}$ and $650{ }^{\circ} \mathrm{C}$, respectively. The white blocks in the figures are retained austenite and some unetched martensite. The microstructures under both conditions were mainly lath martensite structures. Finer lath martensite was found for the sample with $Q_{T}$ $=650{ }^{\circ} \mathrm{C}$ (Fig. 6b), which was smaller and more uniformly distributed than that of $Q_{T}=920{ }^{\circ} \mathrm{C}$.

\section{Hot-Stamping Experiments}

\subsection{Characteristics of the Stamping Part}

The effects of forming temperature on formability and springback were studied using a particularly designed part as shown in Fig. 7. Both the height and width of this part were nonuniform, which changed the formability. The springback performance was hard to control.
Table 3 Mechanical properties of B1500HS post different heat treatments

\begin{tabular}{lllll}
\hline Forming temperature $\left({ }^{\circ} \mathrm{C}\right)$ & $\sigma_{\mathrm{s}}(\mathrm{MPa})$ & $\sigma_{\mathrm{b}}(\mathrm{MPa})$ & $\delta(\%)$ & $\sigma_{\mathrm{b}} \delta(\mathrm{GPa} \%)$ \\
\hline 920 & 882 & 1558 & 10.5 & 16.3 \\
800 & 1090 & 1547 & 10.7 & 16.6 \\
750 & 1093 & 1538 & 10.8 & 16.6 \\
700 & 1045 & 1547 & 11.9 & 18.4 \\
650 & 1087 & 1530 & 12.8 & 19.6 \\
600 & 1067 & 1563 & 12.7 & 19.8 \\
550 & 1067 & 1549 & 12.8 & 19.8 \\
\hline
\end{tabular}



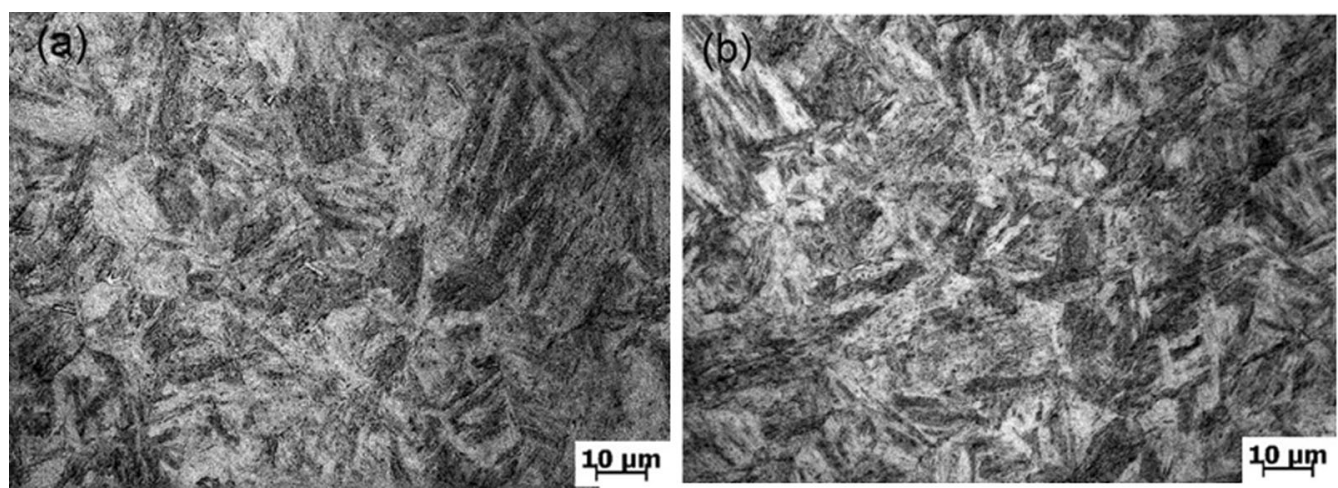

Fig. 6 Microstructures of B1500HS at different forming temperatures. a $Q_{T}=920{ }^{\circ} \mathrm{C}, \mathbf{b} Q_{T}=650{ }^{\circ} \mathrm{C}$

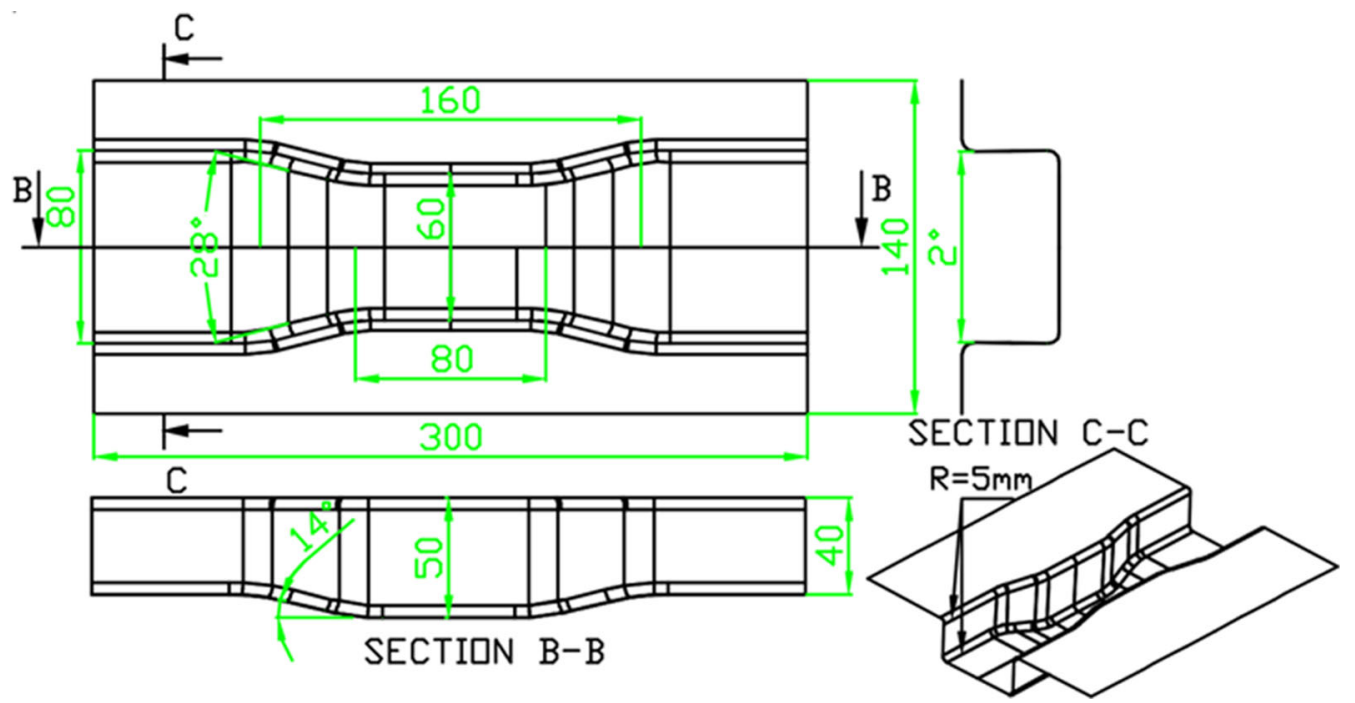

Fig. 7 Geometry of the unequal-height and unequal-width U-shaped Part (unit: mm)

\subsection{Experimental Scheme}

A hot-stamping steel B1500HS blank of the dimensions $300 \mathrm{~mm} \times 190 \mathrm{~mm} \times 1.4 \mathrm{~mm}$ was heated and austenitized at $920{ }^{\circ} \mathrm{C}$ for $5 \mathrm{~min}$. The blank was removed from the furnace and cooled down to a designed temperature $Q_{T}$ before it was transferred to the stamping tool. Both the air cooling method and water-spray method were applied during this stage. The cooling rate of the water-spray method was higher than $80{ }^{\circ} \mathrm{C} \mathrm{s}^{-1}$. The air cooling method had a variable cooling rate that was about $30^{\circ} \mathrm{C} \mathrm{s}^{-1}$ or less. $Q_{T}$ was chosen as $550{ }^{\circ} \mathrm{C}, 600{ }^{\circ} \mathrm{C}, 650{ }^{\circ} \mathrm{C}, 700{ }^{\circ} \mathrm{C}$, and $750^{\circ} \mathrm{C}$, respectively. The stamping and quenching steps were conducted after the blank was transferred to the die, as shown in Fig. 8.

\subsection{Formability Analysis}

Rapid cooling pretreatment affects not only the microstructure and final mechanical properties as discussed

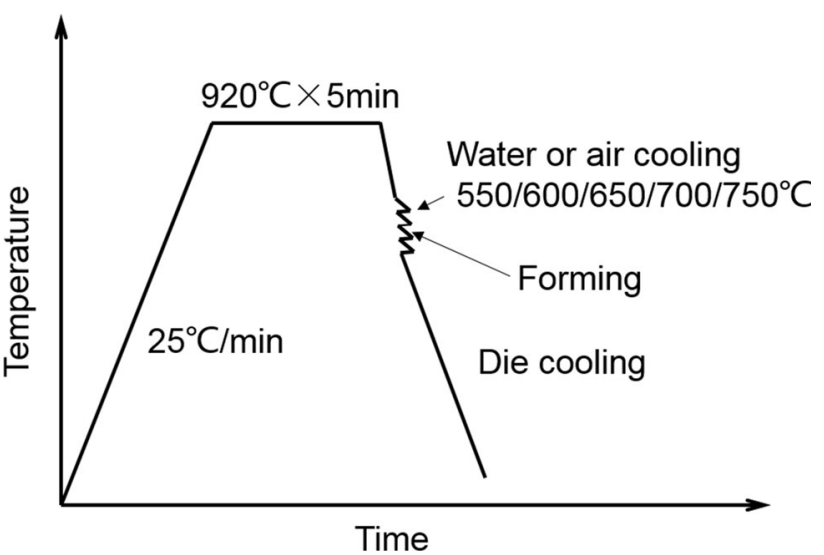

Fig. 8 Hot-stamping experiment scheme with fractional cooling strategy

in literature [14] but also the hot-stamping formability. Figure 9 shows the final post-hot-stamping parts using different fractional cooling strategies. It can be found that the forming temperature significantly affected the forming 

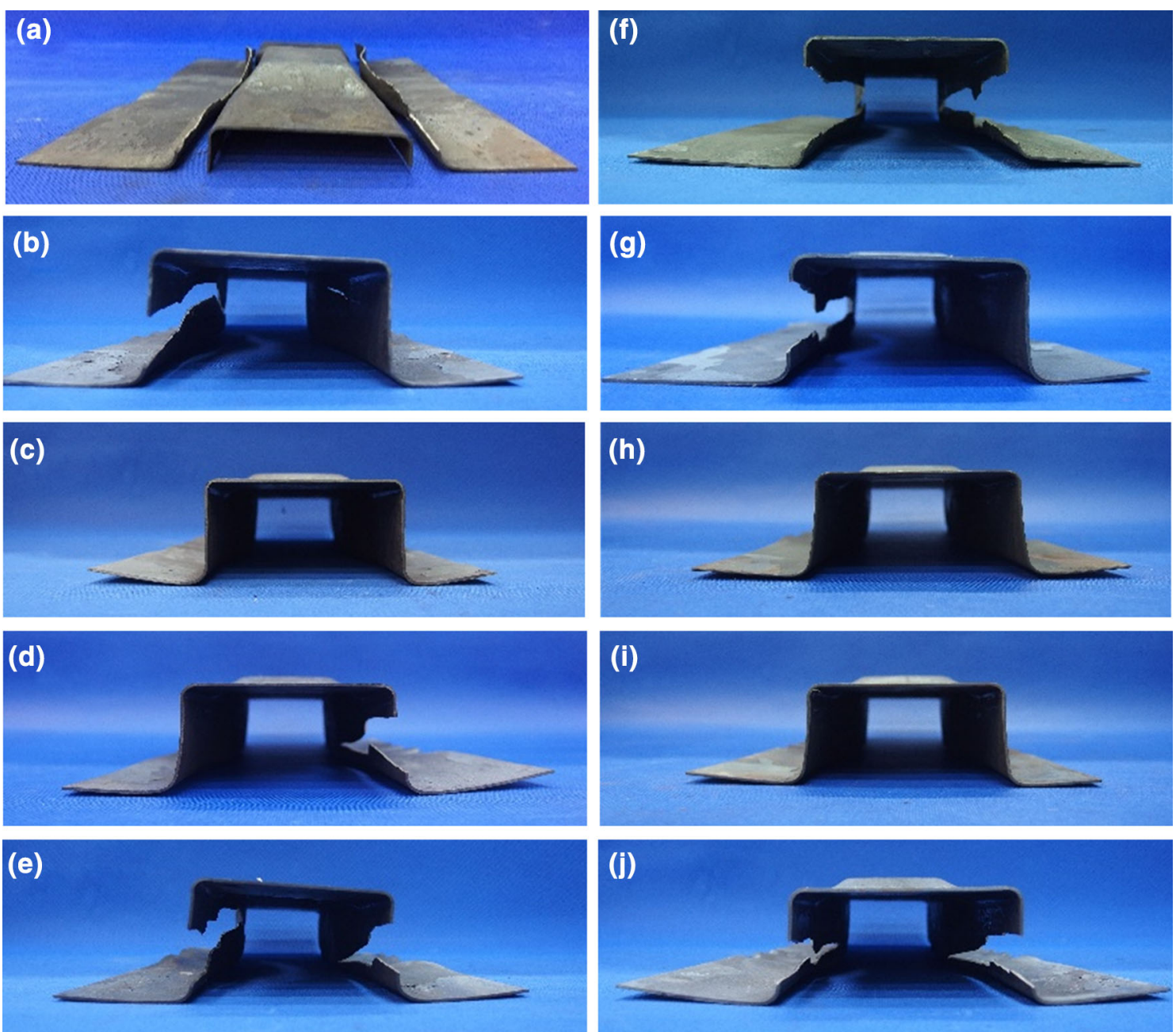

Fig. 9 Hot-stamping parts by integrating the fractional cooling process: with air cooling a $Q_{T}=550{ }^{\circ} \mathrm{C}, \mathbf{b} Q_{T}=600{ }^{\circ} \mathrm{C}, \mathbf{c} Q_{T}=650{ }^{\circ} \mathrm{C}$, d $Q_{T}=700{ }^{\circ} \mathrm{C}$, e $Q_{T}=750{ }^{\circ} \mathrm{C}$, and with spray cooling f $Q_{T}=550{ }^{\circ} \mathrm{C}, \mathbf{g} Q_{T}=600{ }^{\circ} \mathrm{C}$, h $Q_{T}=650{ }^{\circ} \mathrm{C}$, i $Q_{T}=700{ }^{\circ} \mathrm{C}, \mathbf{j} Q_{T}=750{ }^{\circ} \mathrm{C}$

quality of the hot-stamping parts. As mentioned above, the unequal-height and unequal-width characteristics of this part resulted in a tough challenge for the forming process. Fractures happened for high forming temperatures such as $750{ }^{\circ} \mathrm{C}$ and low forming temperatures such as $600{ }^{\circ} \mathrm{C}$ and $550{ }^{\circ} \mathrm{C}$. The part could be successfully formed without fracture only when $Q_{T}$ was set near $650{ }^{\circ} \mathrm{C}$. These results agree with the tensile tests and microstructure analysis. Moreover, using a fast-cooling-rate method during the first cooling stage improved the formability as compared to those using the low-cooling-rate method. Specifically, the water-spray method had a large effective formability range than the air cooling method, which is attributed to the effects of better grain refining when the fast-cooling method was applied.

Normal hot stamping was also performed. The results were very close to those obtained using the air cooling method with $Q_{T}=750{ }^{\circ} \mathrm{C}$ and fractures occurred.

\subsection{Springback Analysis}

Based on the characteristics of this part, seven cross sections were selected to study the springback phenomenon as shown in Fig. 10. The dimensional accuracies were stated by fillet angle $\alpha$ and round angle $\beta$, both of which were measured via a laser-scanning method. The design values of $\alpha$ and $\beta$ were both $90^{\circ}$. The deviations between scanned angles and the design angles are called springback angles.

Figure 11 presents the measured results of the stamping part of the experiments. Figure 11a-g presents the curves of the springback angles at different forming temperatures for the seven selected sections. Figure $11 \mathrm{~h}$ shows the springback distribution at different cross sections when the forming temperature was set as $650{ }^{\circ} \mathrm{C}$. In all these figures, the values of $Q_{T}=800^{\circ} \mathrm{C}$ refers to conventional hotstamping results. 

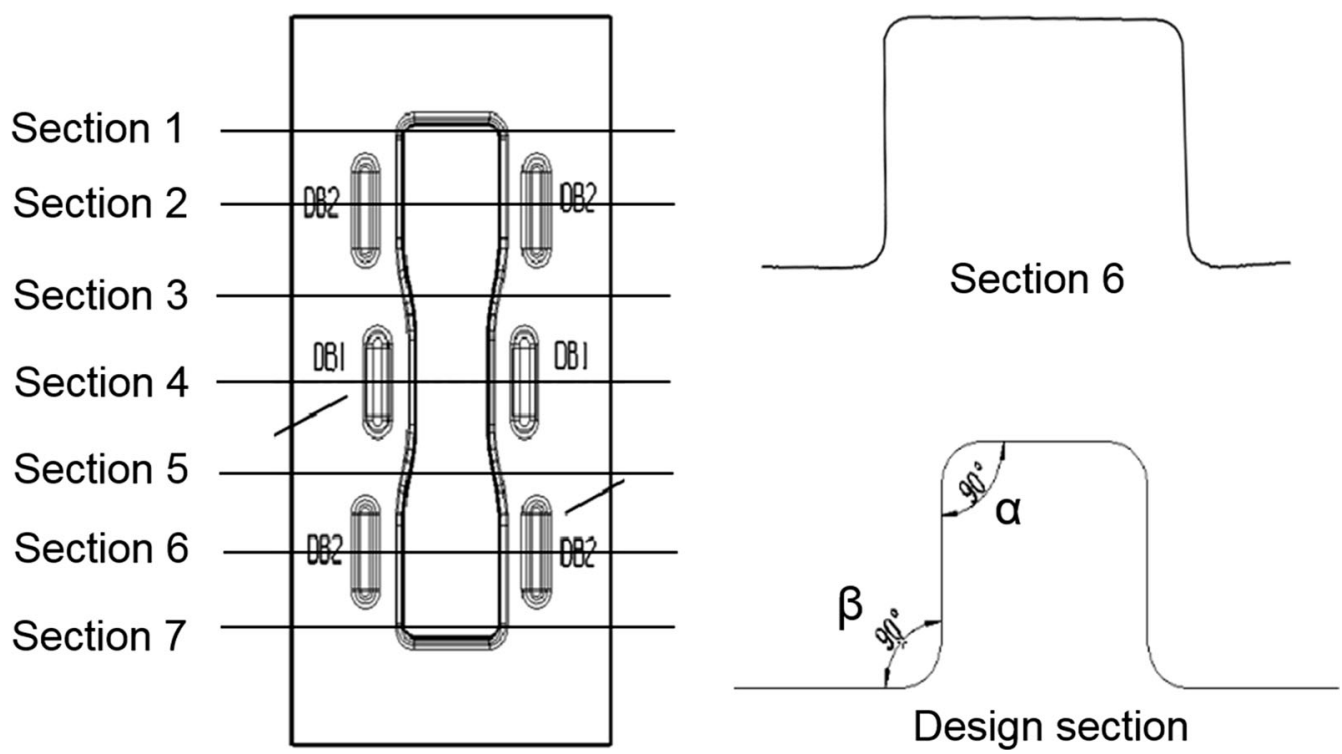

Fig. 10 Section sketch of the springback analysis

Based on Fig. 11a-g, these sections had similar springback rules. All fillet angle deviations had positive values, and all round angle deviations had negative values, suggesting that the final $\alpha>90^{\circ}$ and $\beta<90^{\circ}$ as shown in Fig. 10 in section 6 . Generally, the springback values of the fillet angles were smaller than those of the round angles. The former values were close to $1^{\circ}$, and the maximum values of the latter reached $3.6^{\circ}$, which occurred in sections 1 and 7.

The forming temperatures had notable effects on springback values in all the cross sections. It is hard to find a clear effect law of the forming temperature for all the springback phenomena because the geometry of this part was quite complex. However, it can still be found that the springback values were smaller than others for most sections at $Q_{T}=650{ }^{\circ} \mathrm{C}$. Figure $11 \mathrm{~h}$ presents the springback distributions at this temperature. Similarly, Guo et al. [24] also found that low forming temperatures led to smaller springback than that at high forming temperatures.

\section{Conclusions}

A series of thermal tensile tests, thermal simulation tests, and hot-stamping experiments of an unequal-high and unequal-wide U-shaped part were conducted successively. The main conclusions are:

(1) Forming temperature had a great influence on stamping performance indices, such as the elongation, yield ratio, and hardening exponent. When the forming temperature was set as $650^{\circ} \mathrm{C}$, a small yield ratio, large elongation, and large hardening exponent of B1500HS steel were obtained, indicating good formability.

(2) The forming temperatures studied herein were all above the martensite transformation starting temperature. Thus, the change of forming temperature did not affect the process of martensite transformation, which ensured that the strengths of the final part were all over $1500 \mathrm{MPa}$. Meanwhile, the fast- 

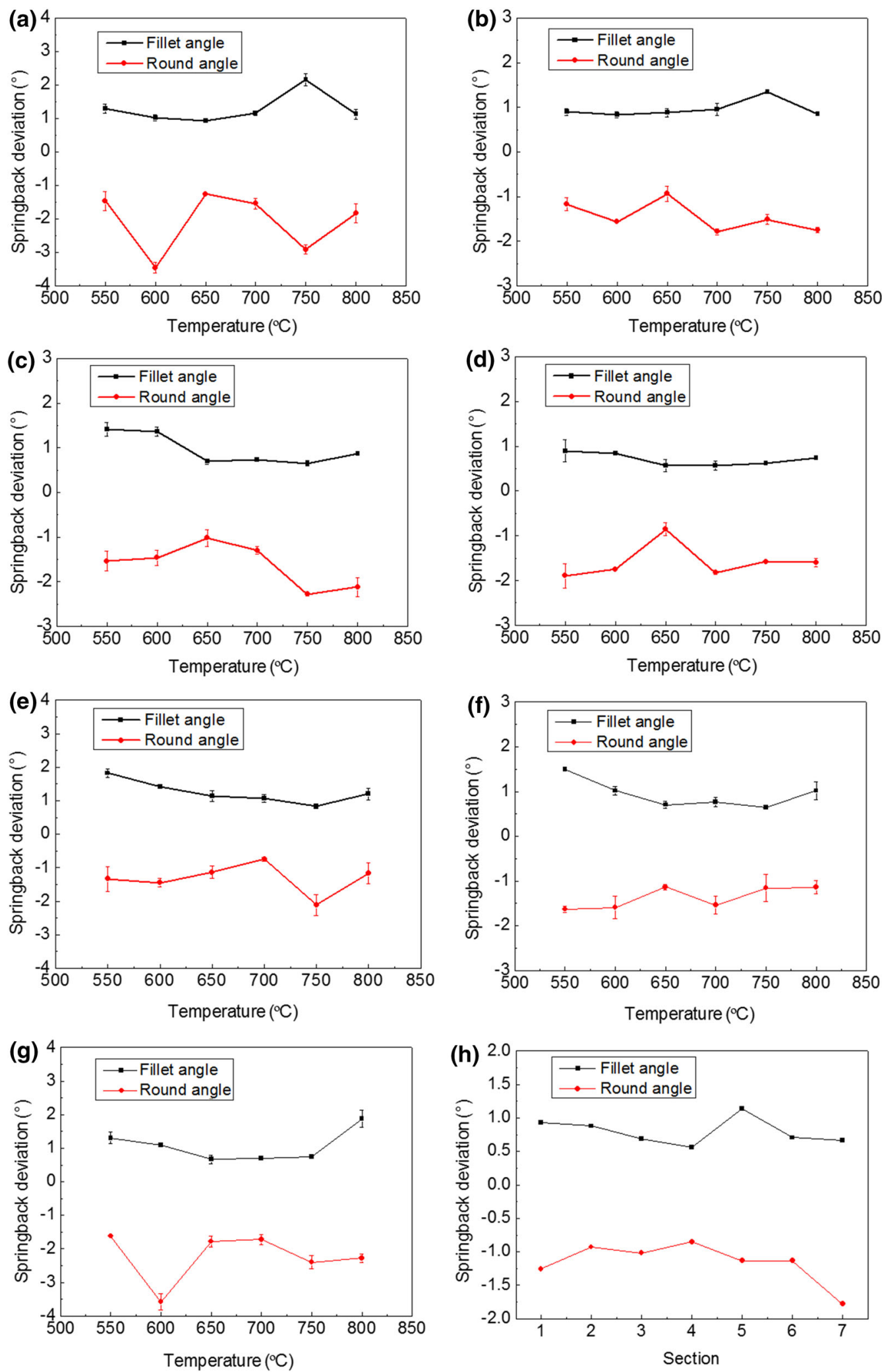

Fig. 11 Springback results of different forming temperatures and cross sections. a Section 1, b Section 2, c Section 3, d Section 4, e Section 5, f Section 6, $\mathbf{g}$ Section $7, \mathbf{h}$ Springback distribution $\left(Q_{T}=650{ }^{\circ} \mathrm{C}\right)$ 
cooling treatment during the first stage refined the grains and moderately improved the plasticity.

(3) The unequal-high and unequal-wide U-shaped part used in the hot-stamping process show that different forming temperatures changed forming qualities, including the fracture generation and springback values. Both of them reached optimal qualities when the forming temperature was set near $650{ }^{\circ} \mathrm{C}$.

Acknowledgements This work was supported by the National Natural Science Foundation of China under Grants 51775336 and U1564203, and the Shanghai Pujiang Program under Grant No. 17PJD019.

\section{References}

[1] W.J. Liu, Acta Metall. Sin. (Engl. Lett.) 27, 373 (2014)

[2] H. Karbasian, A.E. Tekkaya, J. Mater. Process. Technol. 210, $2103(2010)$

[3] P. Hu, N. Ma, L. Liu, Y. Zhu, Theories, Methods and Numerical Technology of Sheet Metal Cold and Hot Forming (Springer, London, 2013)

[4] K. Mori, P.F. Bariani, B.A. Behrens, A. Brosius, S. Bruschi, T. Maeno, M. Merklein, J. Yanagimoto, CIRP Ann. Manuf. Technol. 66, 755 (2017)

[5] H.S. Liu, Z.W. Xing, C.X. Lei, Trans. Nonferrous Met. Soc. China (Eng. Ed.) 22, s542 (2012)

[6] J. Cui, G. Sun, J. Xu, X. Huang, G. Li, Mater. Design 77, 95 (2015)

[7] S.L. Rong, Y.K. Lin, T.W. Chien, in 11th International Conference on Technology of Plasticity, Nagoya, October 2014. Experimental and Theoretical Studies on Formability of $22 \mathrm{MnB} 5$ at Elevated Temperatures by Gleeble Simulator, vol 81 (Springer, Heidelberg, 2014), pp. 1682-1688
[8] Miklós, Zsolt, Lukács, Acta Metall. Sin. (Engl. Lett.) 28, 1471 (2015)

[9] B. He, L. Ying, P. Hu, Y. Yu, X. Zhao, L.W. Zhang, Adv. Mater. Res. 1063, 186 (2014)

[10] M. Naderi, M. Ketabchi, M. Abbasi, W. Bleck, J. Mater. Process. Technol. 211, 1117 (2011)

[11] T. Nishibata, N. Kojima, J. Alloys Compd. 577, S549 (2013)

[12] T. Maeno, K.I. Mori, T. Nagai, CIRP Ann. Manuf. Technol. 63, 301 (2014)

[13] T. Maeno, K.I. Mori, M. Fujimoto, CIRP Ann. Manuf. Technol. 64, 281 (2015)

[14] K. Zhao, Y. Chang, P. Hu, Y. Wu, J. Mater. Process. Technol. 228, 68 (2016)

[15] M. Ganapathy, N. Li, J. Lin, D. Bhattacharjee, in International Conference on the Technology of Plasticity, Cambridge, September 2017. Investigation of a new hot stamping process with improved formability and productivity, vol 207 (Springer, Heidelberg, 2017), pp. 771-776

[16] X. Han, K. Yang, S. Chen, J. Chen, J. Mater. Eng. Perf. 24, 3845 (2015)

[17] B. Tang, Q. Wang, Z. Wang, W. Zheng, Int. J. Mater. Prod. Tech. 46, 255 (2013)

[18] Y. Mu, J. Zhou, B. Wang, Q. Wang, A. Ghiotti, S. Bruschi, Finite Elem. Anal. Des. 147, 34 (2018)

[19] J. Zhou, Y. Mu, B. Wang, J. Zhou, Y. Mu, B. Wang, Int. J. Mech. Sci. (2017). https://doi.org/10.1016/j.ijmecsci.2017.09. 006

[20] P. Hu, N. Ma, Adv. Mater. Res. 156-157, 582 (2011)

[21] N. Li, J. Lin, D.S. Balint, T.A. Dean, J. Mater. Process. Technol. 231, 254 (2016)

[22] K. Liu, B. Chi, Z.M. Shi, J.B. Liu, L. Jian, Adv. Mater. Res. 798, 280 (2013)

[23] G. Venturato, M. Novella, S. Bruschi, A. Ghiotti, R. Shivpuri, in 17th International Conference on Sheet Metal, SHEMET 17, Effects of Phase Transformation in Hot Stamping of 22MnB5 High Strength Steel, vol 183 (Springer, Heidelberg, 2017), pp. 316-321

[24] Y.D. Guo, Key Eng. Mater. 499, 96 (2012) 